\title{
Zoonotic necrotizing myositis caused by Streptococcus equi subsp. zooepidemicus in a farmer
}

\author{
Bård Reiakvam Kittang ${ }^{1 *}$, Veronika Kuchařová Pettersen², Oddvar Oppegaard ${ }^{2,3}$, Dag Harald Skutlaberg ${ }^{2,4}$, \\ Håvard Dale ${ }^{5}$, Harald G. Wiker ${ }^{2,4}$ and Steinar Skrede ${ }^{2,3}$
}

\begin{abstract}
Background: Streptococcus equi subsp. zooepidemicus is a beta-hemolytic group C streptococcus mainly causing infections in domesticated animals. Here we describe the first case of zoonotic necrotizing myositis caused by this bacterium.

Case presentation: The patient was a 73-year-old, previously healthy farmer with two asymptomatic Shetland ponies in his stable. After close contact with the ponies while feeding them, he rapidly developed erythema of his left thigh and sepsis with multiple organ failure. The clinical course was severe and complicated, requiring repetitive surgical excision of necrotic muscle, treatment with vasopressors, mechanical ventilation and continuous venovenous hemofiltration, along with adjunctive hyperbaric oxygen therapy. The patient was discharged from hospital at day 30 , without obvious sequelae.

The streptococcal isolate was identified as Streptococcus equi by MALDI-ToF MS, and was later assigned subspecies identification as S. equi subsp. zooepidemicus. Multilocus sequence typing identified the strain as a novel sequence type (ST 364), closely related to types previously identified in horses and cattle. A focused proteomic analysis revealed that the ST 364 expressed putative virulence factors similar to that of Streptococcus pyogenes, including homologues of the M protein, streptodornases, interleukin 8-protease and proteins involved in the biosynthesis of streptolysin S.

Conclusion: This case illustrates the zoonotic potential of S. equi subsp. zooepidemicus and the importance of early clinical recognition, rapid and radical surgical therapy, appropriate antibiotics and adequate supportive measures when necrotizing soft tissue infection is suspected. The expression of Streptococcus pyogenes-like putative virulence determinants in ST 364 might partially explain the fulminant clinical picture.
\end{abstract}

Keywords: Case report, Zoonosis, Streptococcus equi subsp. zooepidemicus, Necrotizing myositis

\section{Background}

Streptococcus equi subsp. zooepidemicus (S. zooepidemicus) is a beta-haemolytic group C streptococcus able to colonize the upper airways of horses and produce diverse clinical manifestations in domesticated animals, including respiratory tract infections, mastitis and meningitis [1-4]. S. zooepidemicus rarely causes human infection, and the mechanism is supposed to be zoonotic transmission by direct contact with infected or colonized animals or the consumption of unpasteurized milk products [5-8]. This

\footnotetext{
* Correspondence: brki@haraldsplass.no

'Department of Medicine, Haraldsplass Deaconess Hospital, Bergen, Norway Full list of author information is available at the end of the article
}

streptococcus has been associated with a wide range of severe human infections, including cellulitis, pericarditis, toxic shock syndrome, endovascular infections, pneumonia, septicaemia, meningitis, arthritis and spondylodiscitis [5, 9-13]. It has also caused a large outbreak of poststreptococcal glomerulonephritis in Brazil [14].

Necrotizing myositis is a very rare and potentially lethal infection, constituting the most severe form of necrotizing soft tissue infections (NSTI). Monomicrobial NSTI is most often caused by Streptococcus pyogenes (S. pyogenes), and frequently associated with septic shock and high mortality rates [15-17]. NSTI caused by $S$. zooepidemicus was recently documented in a 
dog shortly after subcutaneous vaccination [18], but to our knowledge, human NSTI caused by $S$. zooepidemicus has not been reported previously.

Here we present a case of necrotizing myositis caused by $S$. zooepidemicus in a farmer who was in close contact with his two Shetland ponies prior to the infection.

\section{Case presentation}

A 73 -year-old male patient was transmitted with air ambulance from a local hospital to Haukeland University Hospital (HUH) in western Norway with septic shock and clinical suspicion of NSTI in his left thigh.

His previous medical history included paroxysmal atrial fibrillation, treated with flecainide, and psoriatic arthritis. He was a farmer, with two Shetland ponies in his stable. A few days prior to hospitalization, he had acquired minor abrasions and blisters on his fingers and subsequently been in direct contact with the ponies upon feeding them.

In the afternoon on day 1 , he was admitted to the local hospital with acute pain in his left groin. He rapidly developed symptoms and signs of septic shock. Blood cultures were drawn, and empiric antibiotic therapy with penicillin G, clindamycin and gentamicin was initiated. Computed tomography imaging of the pelvis and left thigh showed possible necrotizing myositis or pyomyositis and he was thereupon rapidly transferred to a tertiary care facility.

Upon admission at HUH day 2 the patient was intubated and maintained an adequate blood pressure of $139 / 61 \mathrm{mmHg}$ on a low-dose noradrenaline-infusion $(0.03 \mu \mathrm{g} / \mathrm{kg} / \mathrm{min})$. His temperature was $38.7^{\circ} \mathrm{C}$ and the pulse rate was 108 per minute. A relatively sharply demarcated erythema in the left thigh was observed, but neither bulla, ecchymosis or skin necrosis was present. Blood cultures and initial blood chemistry analyses were obtained. Further diagnostic and therapeutic strategies were discussed in a multidisciplinary team consisting of an orthopaedic and plastic surgeon, infectious disease consultant and anaesthesiologist. A preoperative magnetic resonance tomography was rapidly performed, revealing probable necrotizing fasciitis and myositis primarily involving the adductor muscles and musculus pectineus in the left thigh. The patient was then transmitted to the operation theatre with a rapidly spreading erythema and a fulminant septic shock, now requiring high-dose noradrenaline infusion $(0.3 \mu \mathrm{g} / \mathrm{kg} / \mathrm{min})$. Initial blood chemistry results were as follows, with normal range values in parentheses:

C-reactive protein $129 \mathrm{mg} / \mathrm{l}(<5 \mathrm{mg} / \mathrm{l})$; leucocytes $1.5 \times 10^{9} / 1\left(3.5 \times 10^{9} / 1\right.$ to $\left.11.0 \times 10^{9} / 1\right)$; neutrophils $1.2 \times 10^{9} / 1\left(1.7 \times 10^{9} / 1\right.$ to $\left.8.2 \times 10^{9} / \mathrm{l}\right)$; haemoglobin $12.4 \mathrm{~g} / \mathrm{dl}(13.4$ to $17.0 \mathrm{~g} / \mathrm{dl})$; thrombocytes $85 \times 10^{9} / \mathrm{l}$ $\left(145 \times 10^{9} / \mathrm{l}\right.$ to $\left.348 \times 10^{9} / \mathrm{l}\right)$; creatinine $63 \mu \mathrm{mol} / \mathrm{l}$
(60 $\mu \mathrm{mol} / \mathrm{l}$ to $105 \mu \mathrm{mol} / \mathrm{l}) ;$ myoglobin $10,323 \mu \mathrm{mol} / \mathrm{l}$ $(<70 \mu \mathrm{mol} / \mathrm{l})$, creatine kinase $9550 \mathrm{U} / \mathrm{l}(40 \mathrm{U} / \mathrm{l}$ to $80 \mathrm{U} / \mathrm{l})$; bilirubin $20 \mu \mathrm{mol} / \mathrm{l} \quad(<19 \mu \mathrm{mol} / \mathrm{l})$; activated partial thromboplastin time $47 \mathrm{~s}$ (30 to $44 \mathrm{~s}$ ); International Normalized Ratio $1.3 \quad(<1.1)$, lactate $4.8 \mathrm{mmol} / \mathrm{l}$ $(0.9 \mathrm{mmol} / \mathrm{l}$ to $1.7 \mathrm{mmol} / \mathrm{l})$, procalcitonin $23.2 \mu \mathrm{g} / \mathrm{l}$ $(<0.1 \mu \mathrm{g} / \mathrm{l})$.

At the first surgical exploration extensive muscle necrosis was found, requiring excision of $m$. adductor longus, along with the anterior part of m. adductor magnus. Profound subcutaneous exudation ("dishwater fluid"), but not frank pus, was also observed, compatible with the diagnosis necrotizing myositis. Perioperative tissue and fluid samples $(n=8)$ were obtained for microbiological and histopathological analyses, and a rapid microscopic evaluation of a Gram stained smear from the site of infection revealed Gram positive diplo- and streptococci. The patient was transmitted to the intensive care unit, with a tentative diagnosis of streptococcal necrotizing myositis.

On day 3 cultures from blood, tissue and fluid grew beta-haemolytic colonies on blood agar. Species identification of the bacterial isolate as Streptococcus equi was performed using matrix-assisted laser desorption ionizationtime of flight mass spectrometry (MALDI-ToF MS), using Microflex $^{\mathrm{m}}$ with the MALDI Biotyper database (Bruker Daltonik, Bremen, Germany) and subsequently group C carbohydrate specificity was determined using a slide agglutination test (Oxoid, Cambridge, United Kingdom). The group $\mathrm{C}$ streptococcus was fully susceptible to all tested antibiotics, with the following MIC-values: penicillin G $0.016 \mathrm{mg} / \mathrm{l}$, ceftriaxone $0.064 \mathrm{mg} / \mathrm{l}$ and clindamycin $0.25 \mathrm{mg} / \mathrm{l}$. In order to obtain a correct subspecies identification, the streptococcal isolate was sent to the national reference laboratory at the Norwegian Veterinary Institute in Oslo for further analyses.

The patient still required treatment with vasopressors and mechanical ventilation, and continuous venovenous hemofiltration was started due to an elevated level of creatinine, oliguria and hyperkalaemia. Gentamicin was discontinued, and therapy with penicillin $\mathrm{G}$ and clindamycin was sustained. A second surgical revision was performed, revealing progressive necrosis of the subcutaneous tissue and muscle of the left thigh that was treated with a resection of almost the entire $m$. adductor magnus and brevis, $m$. pectineus and $m$. gracilis.

The further clinical course was severe and complicated, characterized by a need for repeated surgical excision of necrotic tissue, hyperbaric oxygen (HBO) therapy and sustained intensive care treatment of gradually resolving organ dysfunctions and a nosocomial soft tissue superinfection probably caused by Pseudomonas aeruginosa, which grew from a wound specimen upon clinical deterioration on treatment with penicillin $\mathrm{G}$ and clindamycin. 
Table 1 highlights important aspects of the clinical course and summarizes the major microbiological findings, and Fig. 1 shows the muscular necrosis, infiltration of granulocytes and streptococci found upon histopathological analyses.

On day 11, the tracheostomy was removed. The patient was then transferred from the ICU to the infectious disease ward at $\mathrm{HUH}$ and further on to the local hospital at day 20. He was treated with penicillin and ciprofloxacin until day 30 , and was discharged without any signs of systemic organ dysfunction.

Thereafter, he received physiotherapy on an outpatient basis for a short period and quickly regained adequate muscular function. Twelve months after discharge from hospital he was feeling well, worked full-time and went hiking in the local mountains on a regular basis.

\section{Molecular analyses}

The strain was identified as S. zooepidemicus according to standard microbiological procedures at the Norwegian Veterinary Institute [19]. In order to further identify the strain on a molecular level we performed multilocus sequence typing (MLST), as previously described, with primer pairs targeting seven housekeeping genes [20]. The sequence analyses showed that this particular strain belonged to a new sequence type of $S$. zooepidemicus, ST 364 , closely related to sequence types previously recovered from horses and cattle (http://pubmlst.org/ szooepidemicus).

In order to explore potential virulence determinants of ST 364, a proteomic analysis based on liquid chromatography-tandem mass spectrometry (LC-MS/MS) was performed (Additional files 1 and 2). The analysis was primarily based on a selection of putative virulence factors identified in the only published S. zooepidemicus genome associated with human infection [21], with a particular focus on a search for homologues of selected well-known virulence factors in S. pyogenes.

The proteomic analysis identified altogether 18 proteins linked to S. zooepidemicus virulence (Table 2). For all of these proteins we had derived their relative amounts by employing the proteomic software MaxQuant, which allows for proteins label-free quantification (LFQ) [22]. As a reference protein served elongation factor $\mathrm{TU}$, which is one of the most abundant proteins in most bacterial cells [23]. A number of virulence factors were detected at relatively high levels in ST 364 under in vitro culturing condition. These were cell-surface M-like protein SzM, streptodornase $\mathrm{SdzB}$, serine protease $\mathrm{ScpC} / \mathrm{CepA}$, and several proteins involved in streptolysin $\mathrm{S}$ biosynthesis (SagCDG). In addition, the analysis identified three other proteins engaged in streptolysin $\mathrm{S}$ biosynthesis (SagBHI), a putative peptidoglycan hydrolase (GbpB/SagA/PcsB), several surface-anchored proteins (MlpZ, Fbp, SpaZ and Szp) and enzymes that assist in breaking down the host connective tissue (HylZ) and activate plasminogen (Skc_1, Skc_2).

\section{Discussion}

This first report of zoonotic necrotizing myositis caused by $S$. zooepidemicus illustrates the crucial role of a multidisciplinary approach at admission, rapid clinical identification, early and repeated surgery, adequate supportive measures and appropriate antibiotics in the treatment of NSTI. The findings from a previous study on 89 cases of NSTI showed that time to surgery is an important prognostic factor [24], and it is likely that early surgery and meticulous surgical follow-up was a prerequisite for therapeutic success in our case. The empiric antibiotic treatment consisted of penicillin, clindamycin and gentamicin, in accordance with the national antibiotic guidelines in Norway (http://sites.helsedirektoratet.no/sites/ antibiotikabruk-i-sykehus/Sider/default.aspx).

When the bacterial cause was identified and the antibiotic susceptibility pattern was confirmed, the patient was further treated with a combination of penicillin and clindamycin. Clindamycin has been shown to be superior to beta-lactam-antibiotics in two observational studies on streptococcal NSTI, and furthermore, to reduce mortality of severe GAS infections including toxic shock and NSTI [25-28]. Hence, although ST 364 did not belong to S. pyogenes, the combination of penicillin and clindamycin appeared to be the most sensible antibiotic regimen, in line with the recommendations for treatment of beta-haemolytic NSTI in the IDSA-guidelines [29].

The potential effect of HBO - therapy in NSTI has mainly been evaluated in small, retrospective studies, including patients with varying disease severity and a wide range of different bacteriological aetiologies, and the results are diverging [30-32]. The findings from a recent investigation, however, indicate that the most severely affected NSTI-patients might benefit the most from HBO-therapy [33]. Our patient had life-threatening sepsis with multiorgan-dysfunction and extensive muscle necrosis, and received HBO-therapy on two consecutive days. We believe that prompt and radical surgery along with appropriate antibiotics were the treatment cornerstones in this case, but it is conceivable that HBOtherapy might have contributed to the relatively rapid improvement of the infection.

Zoonotic transmission to man from asymptomatic horses colonized with $S$. zooepidemicus in the upper airways has previously been described [8]. Unfortunately, nasopharyngeal swabs were not obtained from the healthy ponies in the present case. The patient developed sores and abrasions on his fingers prior to the infection, was in direct contact with the ponies while feeding them, and had no direct contact with other 


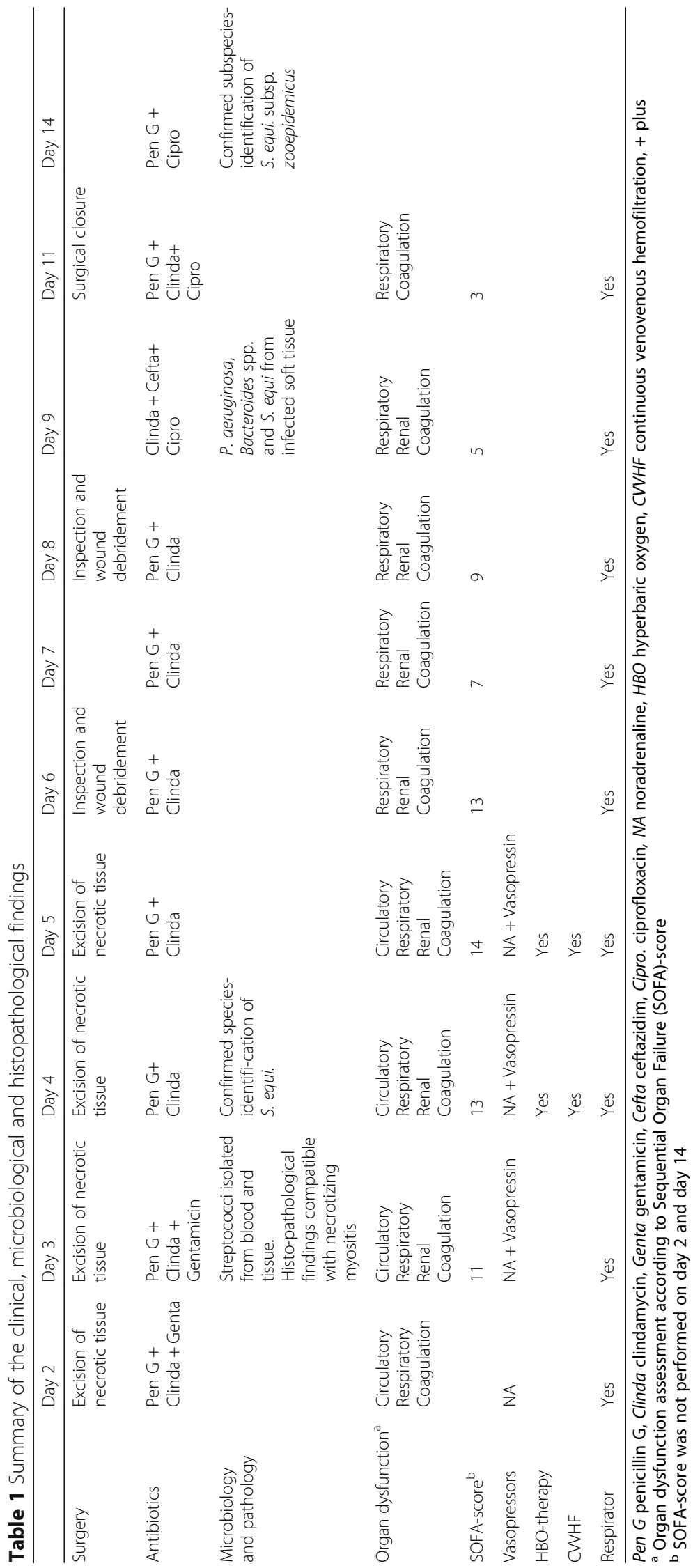




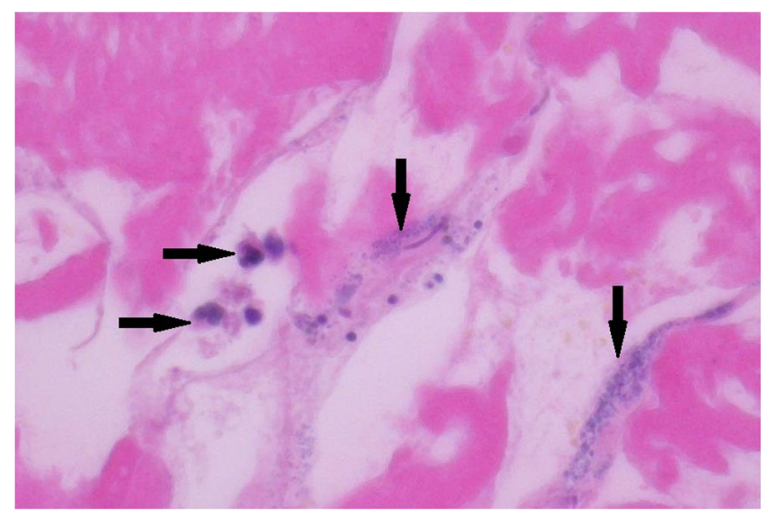

Fig. 1 Histological preparation of muscle biopsy (Hematoxylin-eosin staining, $\times 40$ ), showing infiltration of neutrophil granulocytes (rightward arrows) and aggregates of streptococcal bacteria (downward arrows), surrounded by necrotic muscular tissue

animals before and around the time of infection. Hence, a direct transmission of ST 364 from pony to human is suspected and also supported the close genetic relationship between ST 364 and other S. zooepidemicus sequence types from horses, namely ST 40, ST 138 and ST 214 (http://pubmlst.org/szooepidemicus).
According to a genomic study on animal isolates of Streptococcus equi subspecies equi and zooepidemicus, the former probably has evolved from an ancestral $S$. zooepidemicus into a specialized pathogen primarily responsible for strangles in horses [34]. Furthermore, although $S$. zooepidemicus is able to cause significant respiratory tract infections in horse, they are occasionally associated with asymptomatic nasopharyngeal carriage $[1,35]$. Both $S$. equi subsp. equi and zooepidemicus share extensive homology with $S$. pyogenes, and lateral genetic exchange between these three streptococcal species has been inferred [34]. In a genomic study on a $S$. zooepidemicus strain responsible for an outbreak of post-streptococcal glomerulonephritis, the majority of the putative virulence determinants were $S$. pyogenes-homologues [21]. Moreover, like S. pyogenes, S. zooepidemicus causing human infection tend be associated with a wide range of severe clinical manifestations [5, 9-13].

Knowledge on virulence determinants of severe $S$. zooepidemicus-infections is scarce, particularly in humans. In the aforementioned genomic study by Beres et al., approximately 100 genes homologous to putative or proven virulence factors in other bacteria, primarily S. pyogenes, were identified, including genes encoding

Table 2 Identification of Streptococcus equi subsp. zooepidemicus ST 364 putative virulence factors by proteomic analysis

\begin{tabular}{|c|c|c|c|c|}
\hline \multirow[t]{2}{*}{ Protein name } & \multirow[t]{2}{*}{ Gene name(s) } & \multirow[t]{2}{*}{$\begin{array}{l}\text { Relative cellular } \\
\text { abundance }\end{array}$} & \multicolumn{2}{|c|}{$\begin{array}{l}\text { Relative quantification }{ }^{\mathrm{b}} \\
\text { ( } \log _{2} \text { LFQ intensity) }\end{array}$} \\
\hline & & & Median & Standard deviation \\
\hline Fibronectin/fibrinogen-binding protein & $f b p$ & + & 21.7 & 0.1 \\
\hline Beta-N-acetylglucosaminidase/ Hyaluronidase & hylz & + & 20.7 & 0.4 \\
\hline M-like protein & $m / p Z$ & ++ & 24.9 & 0.2 \\
\hline Secreted antigen GbpB/SagA/PcsB, putative peptidoglycan hydrolase & Sez_0018 & + & 21.0 & 0.1 \\
\hline Streptolysin S biosynthesis protein SagB & $\operatorname{sag} B$ & + & 20.7 & 0.1 \\
\hline Streptolysin S biosynthesis protein SagC & sagC & ++ & 26.1 & 0.1 \\
\hline Streptolysin S biosynthesis protein SagD & sagD & ++ & 25.4 & 0.1 \\
\hline Streptolysin S export protein SagG & $\operatorname{sag} G$ & ++ & 26.8 & 0.1 \\
\hline Streptolysin S export transmembrane permease SagH & sagH & + & 23.1 & 0.1 \\
\hline Streptolysin S export transmembrane permease Sagl & sagl & + & 22.3 & 0.1 \\
\hline Serine endopeptidase, lactocepin, interleukin-8 protease-like protein & scp C/cepA & ++ & 25.1 & 0.1 \\
\hline Streptodornase type B & $s d z B$ & ++ & 26.6 & 0.2 \\
\hline Streptodornase type D & $s d z D$ & ++ & 24.1 & 0.1 \\
\hline Streptokinase; Skc_1 protein & $s k c_{-} 1$ & ++ & 24.3 & 0.1 \\
\hline Uncharacterized streptokinase-like protein; Skc_2 protein & $s k c \_2$ & + & 23.7 & 0.1 \\
\hline Protective antigen-like protein, fibrinogen-and Ig-binding protein & spaz & + & 23.7 & 0.1 \\
\hline Antiphagocytic cell surface-anchored fibrinogen-and lgG Fc-binding protein SzM & szm & +++ & 31.4 & 0.1 \\
\hline Fibrinogen-binding cell surface-anchored protein SzP & $s z p$ & + & 22.0 & 0.3 \\
\hline Elongation factor $\mathrm{Tu}^{\mathrm{c}}$ & tuf & +++ & 31.9 & 0.1 \\
\hline
\end{tabular}

${ }^{a}$ An arbitrary scale of proteins cellular amounts based on the range of $\log _{2}$ LFQ intensities (between 19.6 and 34.0) within the sample: +++ highly abundant protein $\left(\log _{2}\right.$ LFQ intensity: 29-34), ++ protein present in moderate amounts (24-28), + low abundant protein (19-23)

${ }^{\mathrm{b}}$ Label-free quantitative LFQ intensity of a protein is proportional to the quantity of the protein in the sample

${ }^{c}$ Reference protein with high cellular abundance 
factors involved in adhesion, immune response evasion, host cell cytotoxicity, bacterial dissemination and mitogenicity [21]. The highlighted proteomic data on ST 364 presented in this study, indicate a marked expression of homologues of virulent determinants (shown in parenthesis) known to play a role in the pathogenesis of beta-haemolytic streptococcal NSTI, namely the $\mathrm{M}$ protein $(\mathrm{SzM})$, streptodornases $(\mathrm{SdzB})$, interleukin 8-protease ( $\mathrm{SCpC} / \mathrm{CepA})$, and proteins involved in the streptolysin $\mathrm{S}$ biosynthesis (sag C/D/G) [36-39]. Notably, we could not find evidence for superantigen activity in ST 364 , in concordance with in a recent study on horses, where only $50 \%$ of the S. zooepidemicus-isolates contained superantigen-encoding genes [40].

Our molecular data does not allow for firm conclusions on the virulence properties of ST 364, and call for a more thorough genetic and proteomic dissection of this particular strain. Furthermore, although our patient did not have any obvious susceptibility for severe streptococcal disease, the clinical outcome was probably a result of a complex interplay between host factors and bacterial virulence.

Taken together, we speculate that this case story matches the available microbiological, molecular and clinical data on S. zooepidemicus quite well:

We suspect that a S. zooepidemicus-strain, perhaps not fit do produce clinically significant nasopharyngeal infection in the ponies, but potentially armed with virulence properties homologous to those of $S$. pyogenes, was transmitted to a human without known predisposition to infection, causing a severe $S$. pyogenes-like clinical picture.

\section{Conclusion}

This first case report on necrotizing myositis caused by $S$. equi subsp. zooepidemicus illustrates the zoonotic potential and clinical versatility of this betahaemolytic streptococcus. It is also a reminder of the fulminant course streptococcal NSTI can pursue, requiring prompt recognition, extensive surgery, appropriate antibiotics and supportive treatment in the intensive care unit.

The strain ST 364 belonged to a new sequence type closely related to $S$. zooepidemicus-strains previously identified in horses, and expressed S. pyogenes-like putative virulence determinants.

\section{Key points}

- S. zooepidemicus is primarily an animal pathogen, but occasionally fit to produce severe zoonotic infections, including the exceedingly rare manifestation necrotizing myositis
- Necrotizing myositis requires prompt clinical recognition along with adequate surgical, antibiotic and supportive therapy

- The S. pyogenes-like, fulminant course of necrotizing myositis caused by $S$. zooepidemicus might be partially explained by homologous virulence properties

\section{Additional files}

Additional file 1: Proteomic analysis - materials and methods. Methodology of sample preparation for LC-MS/MS analysis and the MS/MS data analysis. (DOC $40 \mathrm{~kb}$ )

Additional file 2: Data sheets - Proteins and Peptides. Results from the proteomic analysis; Streptococcus equi subsp. zooepidemicus proteins detected at 1\% FDR and corresponding peptide sequences detected at 1\% FDR. (XLSX $45 \mathrm{~kb})$

\section{Abbreviations}

CWHF: Continuous venovenous hemofiltration; HBO: Hyperbaric oxygen; HUH: Haukeland University Hospital; LC-MS/MS: Liquid chromatographytandem mass spectrometry; LFQ: Label-free quantification; MALDI-ToF MS: Matrix-assisted laser desorption ionization-time of flight mass spectrometry; MIC: Minimal inhibitory concentration; MLST: Multilocus sequence typing; NA: Noradrenaline; NSTI: Necrotizing soft tissue infections; S. pyogenes: Streptococcus pyogenes; S.zooepidemicus: Streptococcus equi subsp. zooepidemicus

\section{Acknowledgements}

We sincerely thank Anne Bang Nordstoga for information about species identification of ST 364 performed at the Norwegian Veterinary Institute, Oslo, Norway, along with Ellen Berget for preparing the picture of

histopathological findings from muscle biopsy performed at the Department of Pathology at Haukeland University Hospital.

Funding

This study received support from the University of Bergen, and the European Union (FP7/2007-2013) under the grant agreement 305340

Availability of data and materials

All data generated or analysed during this study are included in this published article and its supplementary information files.

\section{Authors' contribution}

BRK drafted the manuscript, performed a literature review and was involved in the design of the molecular analyses, VKP designed and performed the proteomic analyses and revised the manuscript, $O O$ was involved in clinical care, performed the MLST analysis and revised the manuscript, DHS was involved in the microbiological analyses and revised the manuscript, HD was involved in clinical care, obtained surgical samples for microbiological analyses and revised the manuscript, HGW was involved in the design of the proteomic analyses and revised the manuscript SS was involved in clinical care, the design of molecular analyses and revised the manuscript. All authors read and approved the final manuscript.

\section{Competing interests}

The authors declare that they have no competing interests.

\section{Consent for publication}

Written informed consent was obtained from the patient for publication of this case report, including images and any potentially identifying information.

Ethics approval and consent to participate Not applicable. 


\section{Author details}

'Department of Medicine, Haraldsplass Deaconess Hospital, Bergen, Norway. ${ }^{2}$ The Gade Research Group for Infection and Immunity, Department of Clinical Science, University of Bergen, Bergen, Norway. ${ }^{3}$ Department of Medicine, Haukeland University Hospital, Bergen, Norway. ${ }^{4}$ Department of Microbiology, Haukeland University Hospital, Bergen, Norway. ${ }^{5}$ Department of Orthopaedic Surgery, Haukeland University Hospital, Bergen, Norway.

Received: 4 November 2016 Accepted: 10 February 2017

Published online: 15 February 2017

\section{References}

1. Anzai T, Walker JA, Blair MB, Chambers TM, Timoney JF. Comparison of the phenotypes of Streptococcus zooepidemicus isolated from tonsils of healthy horses and specimens obtained from foals and donkeys with pneumonia. Am J Vet Res. 2000;61(2):162-6.

2. Britton AP, Davies JL. Rhinitis and meningitis in two shelter cats caused by Streptococcus equi subspecies zooepidemicus. J Comp Pathol. 2010;143(1):70-4.

3. McClure SR, Koenig R, Hawkins PA. A randomized controlled field trial of a novel trimethoprim-sulfadiazine oral suspension for treatment of Streptococcus equi subsp zooepidemicus infection of the lower respiratory tract in horses. J Am Vet Med Assoc. 2015;246(12):1345-53.

4. Pisoni G, Zadoks RN, Vimercati C, Locatelli C, Zanoni MG, Moroni P. Epidemiological investigation of Streptococcus equi subspecies zooepidemicus involved in clinical mastitis in dairy goats. J Dairy Sci. 2009;92(3):943-51.

5. Bordes-Benitez A, Sanchez-Onoro M, Suarez-Bordon P, Garcia-Rojas AJ, Saez-Nieto JA, Gonzalez-Garcia A, Alamo-Antunez I, Sanchez-Maroto A, Bolanos-Rivero M. Outbreak of Streptococcus equi subsp. zooepidemicus infections on the island of Gran Canaria associated with the consumption of inadequately pasteurized cheese. Eur J Clin Microbiol Infect Dis. 2006:25(4):242-6.

6. Barnham M, Thornton TJ, Lange K. Nephritis caused by Streptococcus zooepidemicus (Lancefield group C). Lancet. 1983;1(8331):945-8.

7. Edwards AT, Roulson M, Ironside MJ. A milk-borne outbreak of serious infection due to Streptococcus zooepidemicus (Lancefield Group C). Epidemiol Infect. 1988;101(1):43-51.

8. Pelkonen S, Lindahl SB, Suomala P, Karhukorpi J, Vuorinen S, Koivula I, Vaisanen T, Pentikainen J, Autio T, Tuuminen T. Transmission of Streptococcus equi subspecies zooepidemicus infection from horses to humans. Emerg Infect Dis. 2013;19(7):1041-8.

9. Held J, Schmitz R, van der Linden M, Nuhrenberg T, Hacker G, Neumann FJ. Purulent pericarditis and pneumonia caused by Streptococcus equi subsp. zooepidemicus. J Med Microbiol. 2014;63(Pt 2):313-6.

10. Korman TM, Boers A, Gooding TM, Curtis N, Visvanathan K. Fatal case of toxic shock-like syndrome due to group $C$ streptococcus associated with superantigen exotoxin. J Clin Microbiol. 2004;42(6):2866-9.

11. McKeage MJ, Humble MW, Morrison RB. Streptococcus zooepidemicus cellulitis and bacteraemia in a renal transplant recipient. Aust N Z J Med. 1990;20(2):177-8.

12. Bhatia R, Bhanot N. Spondylodiskitis secondary to Streptococcus equi subspecies zooepidemicus. Am J Med Sci. 2012;343(1):94-7.

13. Ortel TL, Kallianos J, Gallis HA. Group C streptococcal arthritis: case report and review. Rev Infect Dis. 1990;12(5):829-37.

14. Balter S, Benin A, Pinto SW, Teixeira LM, Alvim GG, Luna E, Jackson D, LaClaire L, Elliott J, Facklam R, et al. Epidemic nephritis in Nova Serrana, Brazil. Lancet. 2000;355(9217):1776-80

15. Chelsom J, Halstensen A, Haga T, Hoiby EA. Necrotising fasciitis due to group A streptococci in western Norway: incidence and clinical features. Lancet. 1994:344(8930):1111-5.

16. Kaul R, McGeer A, Low DE, Green K, Schwartz B. Population-based surveillance for group A streptococcal necrotizing fasciitis: Clinical features, prognostic indicators, and microbiologic analysis of seventy-seven cases. Ontario Group A Streptococcal Study. Am J Med. 1997:103(1):18-24.

17. Bruun T, Kittang BR, de Hoog BJ, Aardal S, Flaatten HK, Langeland N, Mylvaganam H, Vindenes HA, Skrede S. Necrotizing soft tissue infections caused by Streptococcus pyogenes and Streptococcus dysgalactiae subsp. equisimilis of groups C and $\mathrm{G}$ in western Norway. Clin Microbiol Infect. 2013;19(12):E545-50
18. Greijdanus-Van Der Putten SW, Vos JH, Duvekot JR, Paillot R, McLean R, Brokers HJ, Heuvelink AE, Meertens NM, Waller AS. Postvaccinal fata Streptococcus zooepidemicus necrotizing fasciitis in a young dog: a case report. Tijdschr Diergeneeskd. 2014;139(9):24-7.

19. Holth JG, et al. Bergey's manual of determinative bacteriology, Ninth edition. 2002. p. 552-3.

20. Webb K, Jolley KA, Mitchell Z, Robinson C, Newton JR, Maiden MC, Waller A. Development of an unambiguous and discriminatory multilocus sequence typing scheme for the Streptococcus zooepidemicus group. Microbiology. 2008;154(Pt 10):3016-24.

21. Beres SB, Sesso R, Pinto SW, Hoe NP, Porcella SF, Deleo FR, Musser JM. Genome sequence of a Lancefield group C Streptococcus zooepidemicus strain causing epidemic nephritis: new information about an old disease. PLoS One. 2008:3(8), e3026.

22. Cox J, Hein MY, Luber CA, Paron I, Nagaraj N, Mann M. Accurate proteome-wide label-free quantification by delayed normalization and maximal peptide ratio extraction, termed MaxLFQ. Mol Cell Proteomics. 2014;13(9):2513-26

23. Weijland A, Harmark K, Cool RH, Anborgh PH, Parmeggiani A. Elongation factor Tu: a molecular switch in protein biosynthesis. Mol Microbiol. 1992:6(6):683-8.

24. Wong $\mathrm{CH}$, Chang HC, Pasupathy S, Khin LW, Tan JL, Low CO. Necrotizing fasciitis: clinical presentation, microbiology, and determinants of mortality. J Bone Joint Surg Am. 2003;85-a(8):1454-60.

25. Mulla ZD, Leaverton PE, Wiersma ST. Invasive group A streptococcal infections in Florida. South Med J. 2003;96(10):968-73.

26. Zimbelman J, Palmer A, Todd J. Improved outcome of clindamycin compared with beta-lactam antibiotic treatment for invasive Streptococcus pyogenes infection. Pediatr Infect Dis J. 1999;18(12):1096-100.

27. Linner A, Darenberg J, Sjolin J, Henriques-Normark B, Norrby-Teglund A Clinical efficacy of polyspecific intravenous immunoglobulin therapy in patients with streptococcal toxic shock syndrome: a comparative observational study. Clin Infect Dis. 2014;59(6):851-7.

28. Carapetis JR, Jacoby P, Carville K, Ang SJ, Curtis N, Andrews R. Effectiveness of clindamycin and intravenous immunoglobulin, and risk of disease in contacts, in invasive group a streptococcal infections. Clin Infect Dis. 2014;59(3):358-65

29. Stevens DL, Bisno AL, Chambers HF, Dellinger EP, Goldstein EJ, Gorbach SL, Hirschmann JV, Kaplan SL, Montoya JG, Wade JC. Practice guidelines for the diagnosis and management of skin and soft tissue infections: 2014 update by the Infectious Diseases Society of America. Clin Infect Dis. 2014;59(2):e10-52

30. Riseman JA, Zamboni WA, Curtis A, Graham DR, Konrad HR, Ross DS. Hyperbaric oxygen therapy for necrotizing fasciitis reduces mortality and the need for debridements. Surgery. 1990;108(5):847-50.

31. Shupak A, Shoshani O, Goldenberg I, Barzilai A, Moskuna R, Bursztein S. Necrotizing fasciitis: an indication for hyperbaric oxygenation therapy? Surgery. 1995;118(5):873-8.

32. George ME, Rueth NM, Skarda DE, Chipman JG, Quickel RR, Beilman GJ. Hyperbaric oxygen does not improve outcome in patients with necrotizing soft tissue infection. Surg Infect (Larchmt). 2009;10(1):21-8.

33. Shaw JJ, Psoinos C, Emhoff TA, Shah SA, Santry HP. Not just full of hot air: hyperbaric oxygen therapy increases survival in cases of necrotizing soft tissue infections. Surg Infect (Larchmt). 2014;15(3):328-35.

34. Holden MT, Heather Z, Paillot R, Steward KF, Webb K, Ainslie F, Jourdan T, Bason NC, Holroyd NE, Mungall $K$, et al. Genomic evidence for the evolution of Streptococcus equi: host restriction, increased virulence, and genetic exchange with human pathogens. PLoS Pathog. 2009;5(3), e1000346.

35. Acke E, Midwinter AC, Lawrence K, Gordon SJ, Moore S, Rasiah I, Steward K, French N, Waller A. Prevalence of Streptococcus dysgalactiae subsp. equisimilis and S. equi subsp. zooepidemicus in a sample of healthy dogs, cats and horses. N Z Vet J. 2015;63(5):265-71.

36. Walker MJ, Hollands A, Sanderson-Smith ML, Cole JN, Kirk JK, Henningham A, McArthur JD, Dinkla K, Aziz RK, Kansal RG, et al. DNase Sda1 provides selection pressure for a switch to invasive group A streptococcal infection. Nat Med. 2007;13(8):981-5.

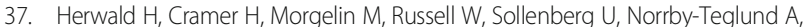
Flodgaard $\mathrm{H}$, Lindbom L, Bjorck L. M protein, a classical bacterial virulence determinant, forms complexes with fibrinogen that induce vascular leakage. Cell. 2004;116(3):367-79. 
38. Kurupati P, Turner CE, Tziona I, Lawrenson RA, Alam FM, Nohadani M, Stamp GW, Zinkernagel AS, Nizet V, Edwards RJ, et al. Chemokinecleaving Streptococcus pyogenes protease SpyCEP is necessary and sufficient for bacterial dissemination within soft tissues and the respiratory tract. Mol Microbiol. 2010;76(6):1387-97.

39. Humar D, Datta V, Bast DJ, Beall B, De Azavedo JC, Nizet V. Streptolysin S and necrotising infections produced by group $\mathrm{G}$ streptococcus. Lancet. 2002;359(9301):124-9.

40. Rash NL, Robinson C, DeSouza N, Nair S, Hodgson H, Steward K, Waller AS, Paillot R. Prevalence and disease associations of superantigens szeF, szeN and szeP in the S. zooepidemicus population and possible functional redundancy of szeF. Res Vet Sci. 2014;97(3):481-7.

Submit your next manuscript to BioMed Central and we will help you at every step:

- We accept pre-submission inquiries

- Our selector tool helps you to find the most relevant journal

- We provide round the clock customer support

- Convenient online submission

- Thorough peer review

- Inclusion in PubMed and all major indexing services

- Maximum visibility for your research

Submit your manuscript at www.biomedcentral.com/submit 